\title{
GMR
}

\section{Comparative analysis of shell color variety and genetic structure among five high-quality freshwater pearl mussel populations}

\author{
L.M. Wu ${ }^{1}$, Z.Y. Bai ${ }^{1,2}$, X.J. Liu ${ }^{1,2}$, C. Jin ${ }^{1}$, H. Yin ${ }^{1}$ and J.L. Li ${ }^{1,2}$ \\ ${ }^{1}$ Key Laboratory of Freshwater Fishery Germplasm Resources, \\ Ministry of Agriculture, Shanghai Ocean University, Shanghai, China \\ ${ }^{2}$ Shanghai Engineering Research Center of Aquaculture, \\ Shanghai Ocean University, Shanghai, China \\ Corresponding author: J.L. Li \\ E-mail: j1li2009@126.com
}

Genet. Mol. Res. 15 (4): gmr15048390

Received January 7, 2016

Accepted February 26, 2016

Published December 2, 2016

DOI http://dx.doi.org/10.4238/gmr15048390

Copyright (C) 2016 The Authors. This is an open-access article distributed under the terms of the Creative Commons Attribution ShareAlike (CC BY-SA) 4.0 License.

\begin{abstract}
Four Hyriopsis cumingii populations, a breeding population (BP), a cultured population (FP), two wild populations from Poyang Lake (PY) and Dongting Lake (DT), and an H. schlegelii population were collected (JX), and the first filial generations (F1) were bred synchronously. The shell nacre polymorphisms, population genetic diversity, and genetic structures of the F1 of each population were analyzed and compared using CIELAB colorimetric measurements and microsatellite markers. The color parameters of the shell nacre $\left(\mathrm{L}^{*}, \mathrm{a}^{*}\right.$, $\mathrm{dE}^{*}$ ) in the BP were significantly different from those in the FP, PY, and JX populations $(\mathrm{P}<0.05)$, whereas the shell nacre color did not differ significantly between the left and right sides of the shells within the same population $(\mathrm{P}>0.05)$. The $\mathrm{BP}$ had relatively darker nacre at the posterior end of the shell, and the color parameters $\left(\mathrm{L}^{*}, \mathrm{a}^{*}, \mathrm{~b}^{*}\right.$,
\end{abstract}

Genetics and Molecular Research 15 (4): gmr15048390 
and $\left.\mathrm{dE}^{*}\right)$ differed significantly from those at the front end $(\mathrm{P}<0.05)$. The five populations showed relatively high levels of genetic diversity $\left(H_{\mathrm{O}}=0.733-0.829\right)$. The genetic distance between the $H$. cumingii populations and $H$. schlegelii was the greatest, whereas that within the H. cumingii populations and between the FP and the PY population was the smallest. All the individuals tested in this study were optimally grouped into four theoretical populations. In conclusion, the BP was significantly different from the base populations of PY and DT in terms of genetic background and phenotypic parameters of shell nacre color, with potential for further genetic improvement.

Key words: Hyriopsis cumingii; Shell nacre; Color; Microsatellite; Genetic structure

\section{INTRODUCTION}

Mollusk shell color is varied, diverse, and the focus of much research. The mechanism underlying the formation of shell color has been studied from two perspectives: genetic inheritance and environmental factors. The results indicate that genetic inheritance plays a decisive role in shell color variations (Liu et al., 2009), followed by environmental factors. The inheritance of shell color follows a simple Mendelian inheritance model (Newkirk, 1980) and is inherited steadily. The shell color of Argopecten irradians is controlled by simple Mendelian inheritance, via one-to-one recessive alleles (Winkler et al., 2001). When controlled by several genes, a particular trait can be obtained by breeding for many generations using a suitable breeding method (Evans and Langdon, 2006).

It is necessary to study the relationships between shell color and other economic characters based on its heritability. Breeders have conducted extensive research into the relationships between shell color and factors such as larval survival rate, growth performance, adaptability, and pearl color (Wada and Komaru, 1994; McGinty et al., 2010; Garcia and Winkler, 2012; Scheil et al., 2013). Artificial breeding for shell color has been performed in various mollusks, and multiple new varieties have been bred successfully (Winkler et al., 2001).

Hyriopsis cumingii is an endemic species, and is the main freshwater aquaculture species of pearl mussel in China (Li et al., 2014) owing to the pearl's smooth pearl nacre and brilliant color. Researchers have found that the shell nacre color of $H$. cumingii is steadily inherited, and, as in the seawater pearl mussel, there is a significant correlation between the pearl color and the nacre color of the donor shell, which supplies the mantle piece (Zhu, 2011). We used two wild populations from Poyang Lake and Dongting Lake as the base populations for breeding, using purple shell nacre and large body mass as the traits of interest. After five generations of population selection with family selection, the purple $H$. cumingii F5 generation was obtained. During variety breeding, immediate analysis of the genetic structure and genealogical relationships within populations can provide the rationale for the breeding method and the selection of breeding parents. It effectively improves the probability of breeding success and reduces the damage from inbreeding (Fu, 2014). In this study, variations in the shell nacre color between breeding $H$. cumingii, a Wuyi-cultured population, a Poyang Lake wild population, a Dongting Lake wild population, and a $H$. schlegelii population were compared and analyzed. Microsatellite technology (simple sequence repeats) was used to

Genetics and Molecular Research 15 (4): gmr15048390 
analyze the genetic diversity and structure within $H$. cumingii to extend our research into the breeding of germplasm resources and to provide a theoretical basis for breeding $H$. cumingii.

\section{MATERIAL AND METHODS}

\section{Parental origin}

The breeding population (BP) was the cultured F5 population of a purple H. cumingii, from our laboratory. The wild populations were collected from Poyang Lake (PY) and Dongting Lake (DT). Hyriopsis schlegelii (JX) was obtained from the seed farm for $H$. schlegelii in Jiangxi Province. All the samples were collected before January 2014, and farmed by Wuyi Weimin Co. Limited, Jinhua City, Zhejiang Province, where the cultured population (FP) was collected.

\section{Seed rearing}

Healthy individuals with powerful water spray and well-developed gonads were selected as parents and cultured by hanging in a greenhouse. The development of the fertilized eggs in the female mussels was inspected irregularly, and the optimal time for larvae collection was predicted. Pelteobagrus fulvidraco was used to foster the larvae, which were cultured in slow-flowing water after detachment. The juveniles were bred for 2 months, until their shell lengths reached $1.2-1.5 \mathrm{~cm}$, at which point they were transferred to a pond and cultured in cages. The cage specifications were $40 \times 40 \times 10 \mathrm{~cm}^{3}$, and 120 juveniles were placed in each cage. The cages were hung $40 \mathrm{~cm}$ below the water. Ten cages of juveniles were established for each group, and bred in Chongming County, Shanghai $\left(31^{\circ} 35^{\prime} \mathrm{N}, 121^{\circ} 31^{\prime} \mathrm{E}\right)$. Daily culture management practices, including fertilization and the regulation of water quality, were maintained during culture.

\section{DNA extraction and determination of shell color polymorphisms}

Following cultivation in cages for 8 months, 60 individuals were selected randomly from each group, and the mantles were stored in absolute ethyl alcohol. Genomic DNA was extracted using the phenol/chloroform method, and the integrity was analyzed with $1 \%$ agarose gel electrophoresis. The purity and concentration of DNA were measured with a NanoDrop 2000c (Thermo Scientific, Wilmington, DE, USA) ultraviolet spectrophotometer. The DNA samples were then diluted to a final concentration of $60 \mathrm{ng} / \mu \mathrm{L}$, and stored at $-20^{\circ} \mathrm{C}$ until analysis. The shells were cleaned, dried in the shade, and stored in the dark.

A Lovibond-RT200 surface colorimeter (Tintometer Limited, Salisbury, UK) was used to measure the CIEL*a*b* parameters of the shell nacre color. Three positions of the shell nacre (the front, middle, and back), on both sides of the shell, were measured three times. The average value for these three color measurements was calculated for each position. The average values for three ipsilateral positions were used as the color parameters for the other side, and the overall averages for the six positions represented the color parameters for each individual. The measured parameters were $L^{*}, a^{*}, b^{*}$, and $\mathrm{dE}^{*}$. $\mathrm{L}^{*}$ is lightness, and when $\mathrm{L}^{*}>0$, the color is whitish, and when $\mathrm{L}^{*}<0$, the color is darkish. When $\mathrm{a}^{*}>0$, the color is reddish, and when $\mathrm{a}^{*}<0$, the color is greenish. When $b^{*}>0$, the color is yellowish, and when $b^{*}<0$, the color is bluish. $\mathrm{dE}^{*}$ represents the color difference between the test sample and the white standard.

Genetics and Molecular Research 15 (4): gmr15048390 


\section{Microsatellite PCR amplification and typing}

Fifteen microsatellite markers from an $H$. cumingii genetic linkage map previously constructed in our laboratory were used in this study (Table 1) (Bai et al., 2015). The primers were synthesized by Tiangen Biotech (Shanghai) Co., Ltd., and fluorescent labels (FAM or HEX) were added at the 5'-ends of the upstream primers. The total volume of the PCRs was $20 \mu \mathrm{L}$, which included $10 \mu \mathrm{L} 2 \mathrm{X}$ Taq PCR MasterMix (Tiangen Biotech), $3 \mu \mathrm{L}$ genomic DNA (60 ng/ $\mu \mathrm{L})$, and $0.5 \mu \mathrm{L}$ each of the upstream and downstream primers $(10 \mathrm{mM})$, made up to $20 \mu \mathrm{L}$ with sterile water. The PCR amplification program was as follows: predenaturation for $3 \mathrm{~min}$ at $94^{\circ} \mathrm{C}$; 35 cycles of denaturation for $30 \mathrm{~s}$ at $94^{\circ} \mathrm{C}$, annealing for $30 \mathrm{~s}$, and extension for $30 \mathrm{~s}$ at $72^{\circ} \mathrm{C}$; and a final extension at $72^{\circ} \mathrm{C}$ for $10 \mathrm{~min}$, after which the samples were stored at $4{ }^{\circ} \mathrm{C}$ until use. The amplified fluorescent PCR products were sequenced by Shanghai MAP Biotech Co., Ltd.

Table 1. Microsatellite primer sequences for Hyriopsis cumingii.
\begin{tabular}{l|c|c|c}
\hline Locus & NCBI accession No. & Locus & NCBI accession No. \\
\hline HcuGA0030 & KJ829805 & HcuGA0682 & KJ830046 \\
\hline HcuGA0051 & KJ829837 & HcuGA0701 & KJ829931 \\
\hline HcuGA0073 & KJ830083 & HcuGA0727 & KJ829781 \\
\hline HcuGA0074 & KJ830105 & HcuGA0747 & KJ830013 \\
\hline HcuGA0122 & KJ829726 & HcuGA0822 & KJ829758 \\
\hline HcuGA0278 & KJ829660 & HcuGA0958 & KJ830078 \\
\hline HcuGA0326 & KJ830115 & & \\
\hline
\end{tabular}

\section{Data processing and analysis}

SPSS 17.0 was used to analyze the diversity of the parameters describing the shell nacre color between groups. Differences were considered significant when $\mathrm{P}<0.05$. Based on the values obtained for color parameters, these populations were clustered according to the shortest Euclidean distances.

The genotype at each locus of each individual was determined based on the fragment size. POPGEN3.2 (Nei, 1978) was used to calculate the number of alleles $\left(N_{\mathrm{A}}\right)$, the effective number of alleles $\left(N_{\mathrm{E}}\right)$, Shannon's information index $(I)$, the observed heterozygosity $\left(H_{\mathrm{O}}\right)$, and the expected heterozygosity $\left(H_{\mathrm{E}}\right)$. CERVUS 3.0 (Kalinowski et al., 2007) was used to calculate the polymorphism information content (PIC), and Hardy-Weinberg equilibrium was tested with the Markov Chain method. ARLEQUIN 3.5 (McGinty et al., 2010) was used to calculate the $F$-statistic $\left(F_{\mathrm{ST}}\right)$ for population genetic differentiation, and POPGEN 3.2 was used to calculate Nei's genetic distances among populations. An unweighted pair group method with arithmetic mean (UPGMA) phylogenetic tree was drawn with MEGA 4.0 (Tamura et al., 2007) based on these genetic distances. STRUCTURE 2.3 was used to analyze the population genetic structures and optimum $K$ values, i.e., the theoretical number of populations based on the population genetic structures.

\section{RESULTS}

\section{Description of nacre color variation among populations}

Descriptive statistics on color parameters for the left side of the nacre in all populations is shown in Table 2. Analysis of the shell nacre color revealed that there were 
significant differences $(\mathrm{P}<0.05)$ in each color parameter between the posterior sections and front sections in the BP, and no obvious differences in the color parameters $(\mathrm{P}>0.05)$ between the front and middle sections $(\mathrm{P}<0.05)$. In the $\mathrm{PY}$ population, all color parameters differed significantly between the posterior section and the middle/front sections $(\mathrm{P}<0.05)$, but the differences between the middle and front sections were not significant, except for $\mathrm{L}^{*}$ and $\mathrm{dE}^{*}$ $(\mathrm{P}>0.05)$. There were no obvious differences in most of the color parameters for shell nacre color among three sections in other populations. Those on the right side of the five populations were roughly similar to those on the left side (Table 3).

Table 2. Descriptive statistics of the color parameters measured for the nacre on the left side of the shells.

\begin{tabular}{l|c|c|c|c}
\hline Groups & $\mathrm{L}^{*}$ & $\mathrm{a}^{*}$ & $\mathrm{~b}^{*}$ & $\mathrm{dE}^{*}$ \\
\hline BP1 & $58.81 \pm 5.84^{\mathrm{a}}$ & $3.53 \pm 2.41^{\mathrm{b}}$ & $-15.52 \pm 2.46^{\mathrm{b}}$ & $44.51 \pm 5.47^{\mathrm{c}}$ \\
\hline BP2 & $55.40 \pm 7.08^{\mathrm{a}}$ & $5.82 \pm 2.91^{\mathrm{b}}$ & $-16.39 \pm 3.39^{\mathrm{b}}$ & $48.33 \pm 6.56^{\mathrm{b}}$ \\
\hline BP3 & $48.56 \pm 9.69^{\mathrm{b}}$ & $7.88 \pm 3.19^{\mathrm{a}}$ & $-2.56 \pm 6.62^{\mathrm{a}}$ & $52.85 \pm 9.55^{\mathrm{a}}$ \\
\hline FP1 & $63.47 \pm 7.89^{\mathrm{a}}$ & $0.90 \pm 1.21^{\mathrm{b}}$ & $-5.41 \pm 4.83^{\mathrm{b}}$ & $32.92 \pm 12.04^{\mathrm{a}}$ \\
\hline FP2 & $64.05 \pm 5.79^{\mathrm{a}}$ & $3.18 \pm 2.12^{\mathrm{a}}$ & $0.76 \pm 6.00^{\mathrm{a}}$ & $36.61 \pm 6.08^{\mathrm{b}}$ \\
\hline FP3 & $66.22 \pm 5.13^{\mathrm{a}}$ & $2.45 \pm 1.62^{\mathrm{a}}$ & $-6.75 \pm 4.45^{\mathrm{b}}$ & $41.02 \pm 4.07^{\mathrm{a}}$ \\
\hline PY1 & $64.24 \pm 4.91^{\mathrm{b}}$ & $0.70 \pm 1.93^{\mathrm{b}}$ & $-19.56 \pm 3.09^{\mathrm{b}}$ & $37.15 \pm 4.44^{\mathrm{b}}$ \\
\hline PY3 & $68.48 \pm 5.06^{\mathrm{a}}$ & $0.73 \pm 2.09^{\mathrm{b}}$ & $-18.99 \pm 3.92^{\mathrm{b}}$ & $37.05 \pm 7.86^{\mathrm{b}}$ \\
\hline DT1 & $66.33 \pm 8.48^{\mathrm{a}}$ & $3.17 \pm 4.04^{\mathrm{a}}$ & $-13.02 \pm 5.81^{\mathrm{a}}$ & $42.41 \pm 3.54^{\mathrm{a}}$ \\
\hline DT2 & $59.30 \pm 3.88^{\mathrm{a}}$ & $2.19 \pm 1.49^{\mathrm{b}}$ & $-10.88 \pm 3.76^{\mathrm{a}}$ & $41.07 \pm 4.24^{\mathrm{a}}$ \\
\hline JX1 & $61.27 \pm 4.68^{\mathrm{a}}$ & $1.95 \pm 1.48^{\mathrm{b}}$ & $-12.69 \pm 3.99^{\mathrm{a}}$ & $41.72 \pm 8.37^{\mathrm{a}}$ \\
\hline JX2 & $60.93 \pm 8.79^{\mathrm{a}}$ & $3.20 \pm 2.28^{\mathrm{a}}$ & $-9.83 \pm 6.39^{\mathrm{a}}$ & $34.93 \pm 12.67^{\mathrm{a}}$ \\
\hline JX3 & $62.40 \pm 4.58^{\mathrm{a}}$ & $0.53 \pm 1.06^{\mathrm{b}}$ & $-15.14 \pm 3.62^{\mathrm{a}}$ & $35.06 \pm 14.04^{\mathrm{a}}$ \\
\hline
\end{tabular}

Different lowercase letters represent a significant difference within the same row $(\mathrm{P}<0.05)$. PY: Poyang Lake wild population; JX: Hyriopsis schlegelii population; DT: Dongting Lake wild population; FP: cultured population; BP: breeding population.

Table 3. Descriptive statistics of the color parameters measured for nacre on the right sides of shells.

\begin{tabular}{l|c|c|c|c}
\hline Groups & $\mathrm{L}^{*}$ & $\mathrm{a}^{*}$ & $\mathrm{~b}^{*}$ & $\mathrm{dE}^{*}$ \\
\hline BP1 & $60.11 \pm 5.55^{\mathrm{a}}$ & $3.19 \pm 2.31^{\mathrm{b}}$ & $-15.66 \pm 2.65^{\mathrm{b}}$ & $43.35 \pm 5.00^{\mathrm{c}}$ \\
\hline BP2 & $56.03 \pm 5.92^{\mathrm{a}}$ & $5.87 \pm 2.66^{\mathrm{b}}$ & $-15.73 \pm 4.10^{\mathrm{b}}$ & $47.55 \pm 5.41^{\mathrm{b}}$ \\
\hline BP3 & $49.75 \pm 10.43^{\mathrm{b}}$ & $7.28 \pm 3.36^{\mathrm{a}}$ & $-3.16 \pm 6.12^{\mathrm{a}}$ & $51.56 \pm 10.38^{\mathrm{a}}$ \\
\hline FP1 & $64.59 \pm 7.11^{\mathrm{a}}$ & $0.94 \pm 1.62^{\mathrm{b}}$ & $-5.37 \pm 4.86^{\mathrm{b}}$ & $32.34 \pm 11.24^{\mathrm{b}}$ \\
\hline FP2 & $65.56 \pm 6.93^{\mathrm{a}}$ & $3.32 \pm 2.13^{\mathrm{a}}$ & $0.77 \pm 5.82^{\mathrm{a}}$ & $36.16 \pm 11.05^{\mathrm{a}}$ \\
\hline FP3 & $66.23 \pm 4.62^{\mathrm{a}}$ & $2.29 \pm 1.38^{\mathrm{a}}$ & $-6.20 \pm 4.43^{\mathrm{b}}$ & $39.15 \pm 3.45^{\mathrm{b}}$ \\
\hline PY1 & $66.64 \pm 4.55^{\mathrm{a}}$ & $0.20 \pm 1.82^{\mathrm{b}}$ & $-19.86 \pm 3.83^{\mathrm{b}}$ & $36.94 \pm 4.85^{\mathrm{a}}$ \\
\hline PY3 & $68.97 \pm 5.30^{\mathrm{a}}$ & $0.48 \pm 2.11^{\mathrm{b}}$ & $-19.49 \pm 3.57^{\mathrm{b}}$ & $38.14 \pm 8.42^{\mathrm{a}}$ \\
\hline DT1 & $65.32 \pm 9.26^{\mathrm{a}}$ & $3.59 \pm 4.19^{\mathrm{a}}$ & $-12.99 \pm 6.28^{\mathrm{a}}$ & $42.85 \pm 3.98^{\mathrm{a}}$ \\
\hline DT3 & $59.10 \pm 4.31^{\mathrm{a}}$ & $2.34 \pm 1.39^{\mathrm{a}}$ & $-11.84 \pm 3.55^{\mathrm{a}}$ & $41.72 \pm 4.27^{\mathrm{ab}}$ \\
\hline JX1 & $61.14 \pm 4.88^{\mathrm{a}}$ & $1.82 \pm 1.56^{\mathrm{a}}$ & $-14.42 \pm 3.39^{\mathrm{a}}$ & $39.08 \pm 5.56^{\mathrm{b}}$ \\
\hline JX2 & $63.12 \pm 6.23^{\mathrm{a}}$ & $2.91 \pm 2.37^{\mathrm{a}}$ & $-10.19 \pm 6.51^{\mathrm{a}}$ & $34.46 \pm 12.76^{\mathrm{a}}$ \\
\hline JX3 & $63.15 \pm 4.10^{\mathrm{ab}}$ & $0.39 \pm 1.20^{\mathrm{b}}$ & $-14.98 \pm 3.44^{\mathrm{a}}$ & $36.44 \pm 13.06^{\mathrm{a}}$ \\
\hline Diff & $61.75 \pm 6.06^{\mathrm{b}}$ & $1.04 \pm 1.28^{\mathrm{a}}$ & $-17.16 \pm 4.13^{\mathrm{b}}$ & $32.45 \pm 12.06^{\mathrm{a}}$ \\
\hline
\end{tabular}

Different lowercase letters represent a significant difference within the same row $(\mathrm{P}<0.05)$. For abbreviations, see Table 2.

The shell nacre color did not differ significantly between the left and right sides of the shells in each population $(\mathrm{P}>0.05$; Table 4$)$. Thus, the BP differed significantly from other populations for the color parameters $\mathrm{L}^{*}, \mathrm{a}^{*}$, and $\mathrm{dE}^{*}(\mathrm{P}<0.05)$, but nonsignificantly for $\mathrm{b}^{*}(\mathrm{P}>0.05)$.

Genetics and Molecular Research 15 (4): gmr15048390 
Table 4. Comparison of color parameters measured for shell nacre between the left and right sides of shells within the same population and among different populations.

\begin{tabular}{|c|c|c|c|c|c|}
\hline Groups & & $\mathrm{L}^{*}$ & $\mathrm{a}^{*}$ & $\mathrm{~b}^{*}$ & $\mathrm{dE}^{*}$ \\
\hline \multirow[t]{2}{*}{$\mathrm{BP}$} & $\mathrm{L}$ & $54.26 \pm 5.22^{\mathrm{a}}$ & $5.74 \pm 2.18^{\mathrm{a}}$ & $-11.49 \pm 7.75^{\mathrm{a}}$ & $48.56 \pm 4.17^{\mathrm{a}}$ \\
\hline & $\mathrm{R}$ & $55.30 \pm 5.22^{\mathrm{a}}$ & $5.45 \pm 2.08^{\mathrm{a}}$ & $-11.52 \pm 7.24^{\mathrm{a}}$ & $47.49 \pm 4.11^{\mathrm{a}}$ \\
\hline \multirow[t]{2}{*}{ FP } & $\mathrm{L}$ & $64.58 \pm 1.45^{\mathrm{a}}$ & $2.18 \pm 1.16^{\mathrm{a}}$ & $-3.80 \pm 4.01^{\mathrm{a}}$ & $34.80 \pm 1.85^{\mathrm{a}}$ \\
\hline & $\mathrm{R}$ & $65.46 \pm 0.82^{\mathrm{a}}$ & $2.18 \pm 1.20^{\mathrm{a}}$ & $-3.60 \pm 3.81^{\mathrm{a}}$ & $34.06 \pm 1.50^{\mathrm{a}}$ \\
\hline \multirow[t]{2}{*}{ PY } & $\mathrm{L}$ & $66.35 \pm 2.12^{\mathrm{a}}$ & $1.53 \pm 1.42^{\mathrm{a}}$ & $-17.19 \pm 3.62^{\mathrm{a}}$ & $38.41 \pm 2.26^{\mathrm{a}}$ \\
\hline & $\mathrm{R}$ & $66.97 \pm 1.85^{\mathrm{a}}$ & $1.42 \pm 1.88^{\mathrm{a}}$ & $-17.44 \pm 3.86^{\mathrm{a}}$ & $38.07 \pm 1.11^{\mathrm{a}}$ \\
\hline \multirow[t]{2}{*}{ DT } & $\mathrm{L}$ & $60.27 \pm 0.99^{\mathrm{a}}$ & $2.45 \pm 0.66^{\mathrm{a}}$ & $-11.13 \pm 1.45^{\mathrm{a}}$ & $41.73 \pm 0.67^{\mathrm{a}}$ \\
\hline & $\mathrm{R}$ & $61.12 \pm 2.01^{\mathrm{a}}$ & $2.36 \pm 0.55^{\mathrm{a}}$ & $-12.15 \pm 2.13^{\mathrm{a}}$ & $41.21 \pm 1.93^{\mathrm{a}}$ \\
\hline \multirow[t]{2}{*}{ JX } & $\mathrm{L}$ & $63.07 \pm 0.76^{\mathrm{a}}$ & $1.35 \pm 1.08^{\mathrm{a}}$ & $-15.50 \pm 1.57^{\mathrm{a}}$ & $34.64 \pm 0.61^{\mathrm{a}}$ \\
\hline & $\mathrm{R}$ & $63.48 \pm 1.91^{\mathrm{a}}$ & $1.11 \pm 0.75^{\mathrm{a}}$ & $-15.60 \pm 1.36^{\mathrm{a}}$ & $34.45 \pm 1.99^{\mathrm{a}}$ \\
\hline $\mathrm{BP}$ & $\mathrm{BM}$ & $54.62 \pm 8.97^{\mathrm{a}}$ & $5.50 \pm 3.36^{\mathrm{a}}$ & $-10.95 \pm 7.22^{b}$ & $47.89 \pm 8.18^{\mathrm{a}}$ \\
\hline FP & $\mathrm{BM}$ & $64.90 \pm 6.39^{\mathrm{b}}$ & $1.94 \pm 1.96^{\mathrm{b}}$ & $-3.58 \pm 5.85^{\mathrm{a}}$ & $32.89 \pm 10.13^{\circ}$ \\
\hline PY & $\mathrm{BM}$ & $66.55 \pm 6.69^{\mathrm{b}}$ & $1.41 \pm 3.06^{\mathrm{b}}$ & $-13.63 \pm 4.28^{\mathrm{b}}$ & $37.30 \pm 7.86^{\text {bc }}$ \\
\hline DT & $\mathrm{BM}$ & $60.58 \pm 5.82^{\mathrm{ab}}$ & $2.16 \pm 1.91^{\mathrm{b}}$ & $-11.40 \pm 4.91^{b}$ & $41.49 \pm 6.28^{\mathrm{ab}}$ \\
\hline JX & $\mathrm{BM}$ & $63.15 \pm 5.93^{\mathrm{b}}$ & $1.12 \pm 1.66^{\mathrm{b}}$ & $-14.08 \pm 3.80^{b}$ & $34.10 \pm 13.20^{\circ}$ \\
\hline
\end{tabular}

$\mathrm{L}$ : shell nacre on the left side; R: shell nacre on the right side; BM: average population value. For other abbreviations, see Table 2. Different lowercase letters represent a significant difference within the same row $(\mathrm{P}<0.05)$.

\section{Microsatellite polymorphisms and population genetic diversity}

The amplification results for 15 pairs of microsatellite primers in five populations are shown in Table 5. $N_{\mathrm{A}}$ was $27-52, N_{\mathrm{E}}$ was $2.63-19.02, H_{\mathrm{O}}$ was $0.539-0.973, H_{\mathrm{E}}$ was $0.620-0.949$, and PIC was 0.607-0.974. All loci were highly polymorphic (PIC >0.5).

Table 5. Number of alleles $\left(N_{\mathrm{A}}\right)$, effective number of alleles $\left(N_{\mathrm{E}}\right)$, observed $\left(H_{\mathrm{O}}\right)$ and expected heterozygosities $\left(H_{\mathrm{E}}\right)$, and polymorphism information content (PIC) for 15 microsatellite loci.

\begin{tabular}{l|c|c|c|c|c}
\hline Locus & $N_{\mathrm{A}}$ & $N_{\mathrm{E}}$ & $H_{\mathrm{O}}$ & $H_{\mathrm{E}}$ & PIC \\
\hline HcuGA0030 & 38 & 15.59 & 0.890 & 0.937 & 0.932 \\
\hline HcuGA0074 & 48 & 17.07 & 0.736 & 0.943 & 0.939 \\
\hline HcuGA0822 & 32 & 11.60 & 0.893 & 0.915 & 0.908 \\
\hline HcuGA0073 & 27 & 11.97 & $0.909^{* *}$ & 0.918 & 0.911 \\
\hline HcuGA0682 & 28 & 12.96 & $0.662^{* *}$ & 0.924 & 0.918 \\
\hline HcuGA0701 & 29 & 9.79 & $0.632^{* *}$ & 0.899 & 0.889 \\
\hline HcuGA0747 & 29 & 14.45 & 0.587 & 0.933 & 0.927 \\
\hline HcuGA0122 & 37 & 2.63 & 0.539 & 0.620 & 0.607 \\
\hline HcuGA0051 & 38 & 14.79 & 0.836 & 0.934 & 0.928 \\
\hline HcuGA0336 & 38 & 13.02 & $0.737^{* *}$ & 0.925 & 0.918 \\
\hline HcuGA0752 & 52 & 5.98 & 0.759 & 0.834 & 0.974 \\
\hline HcuGA0278 & 41 & 11.69 & 0.887 & 0.916 & 0.909 \\
\hline HcuGA0727 & 44 & 19.02 & 0.973 & 0.949 & 0.945 \\
\hline Mean & 33 & 8.99 & 0.880 & 0.890 & 0.880 \\
\hline
\end{tabular}

**Indicates a highly significant departure from Hardy-Weinberg equilibrium $(\mathrm{P}<0.01)$.

The genetic diversity of the five populations is shown in Table 6. The FP possessed the highest values for almost all genetic parameters measured, whereas the JX population possessed the lowest values. Among the BP, PY, and DT populations, the average $N_{\mathrm{A}}$ was the highest in the BP (22.07) and the lowest in the PY population (19.00). $N_{\mathrm{E}}$ was the highest in the PY population (8.782) and the lowest in the BP. Shannon's information index was highest in 
the BP $(I=2.398)$ and the lowest in the DT population $(I=2.389) . H_{\mathrm{O}}(0.892)$ and $H_{\mathrm{E}}(0.876)$ were the highest in the PY population, whereas $H_{\mathrm{O}}$ was the lowest in the BP $(0.798)$, and $H_{\mathrm{E}}$ was the lowest in the DT population (0.864).

\section{Table 6. Genetic diversity among populations.}

\begin{tabular}{l|c|c|c|c|c}
\hline Parameter & BP & FP & PY & DT & JX \\
\hline$N_{\mathrm{A}}$ & 22.07 & 23.47 & 19.00 & 21.33 & 17.60 \\
\hline$N_{\mathrm{E}}$ & 7.583 & 10.560 & 8.782 & 7.909 & 6.375 \\
\hline$I$ & 2.398 & 2.627 & 2.395 & 2.389 & 2.164 \\
\hline$H_{\mathrm{O}}$ & 0.798 & 0.810 & 0.829 & 0.812 & 0.733 \\
\hline$H_{\mathrm{E}}$ & 0.867 & 0.904 & 0.876 & 0.864 & 0.836 \\
\hline PIC & 0.848 & 0.889 & 0.858 & 0.687 & 0.815 \\
\hline
\end{tabular}

\section{Analysis of genetic differentiation and genetic distances among populations}

The genetic differentiation among the populations studied is shown in Table 7. The range of the genetic differentiation coefficient, $F_{\mathrm{ST}}$, among the five populations was 0.02440.0689 , and the average value was 0.0492 . The range of the genetic differentiation indices between $H$. cumingii and $H$. schlegelii was $0.0586-0.0689\left(F_{\mathrm{ST}}>0.05\right)$, indicating moderate differentiation. The genetic differentiation index between the BP and the DT populations was 0.0504 , indicating moderate differentiation $\left(F_{\mathrm{ST}}>0.05\right)$. The range of the genetic differentiation indices among the other populations was 0.0244-0.0470, indicating slight differentiation $\left(F_{\text {ST }}\right.$ $<0.05)$. The genetic distances $\left(D_{\mathrm{A}}\right)$ among the populations are shown in Table 7 . The genetic distance between the PY and the FP was shortest $\left(D_{\mathrm{A}}=0.2617\right)$, whereas that between the DT and JX populations was the largest $\left(D_{\mathrm{A}}=0.5342\right)$.

Table 7. Nei's genetic distances $\left(D_{\mathrm{A}}\right.$, below the diagonal) and F statistics ( $F_{\mathrm{ST}}$, above the diagonal) among the populations.

\begin{tabular}{l|c|c|c|c|c}
\hline Groups & PY & BP & FP & JX & DT \\
\hline PY & - & $0.0452^{*}$ & $0.0244^{*}$ & $0.0637^{*}$ & $0.0470^{*}$ \\
\hline BP & 0.4073 & - & $0.0326^{*}$ & $0.0675^{*}$ & $0.0504^{*}$ \\
\hline FP & 0.2617 & 0.3116 & - & $0.0586^{*}$ & $0.0338^{*}$ \\
\hline JX & 0.5062 & 0.4866 & 0.4702 & - & $0.0689^{*}$ \\
\hline
\end{tabular}

*Indicates a significant difference $(\mathrm{P}<0.05)$.

\section{Cluster analysis}

A systematic clustering method using the shortest Euclidean distances was applied. The tree constructed with the average values for the shell nacre color parameters of each population (Figure 1) showed that the PY and JX populations clustered most closely, and then clustered sequentially with the DT and FP populations, clustering least closely with the BP. An UPGMA tree based on genetic distances (Figure 2) showed that the PY and FP populations clustered more closely, then clustered sequentially with the BP and DT populations, and lastly with the JX population. 


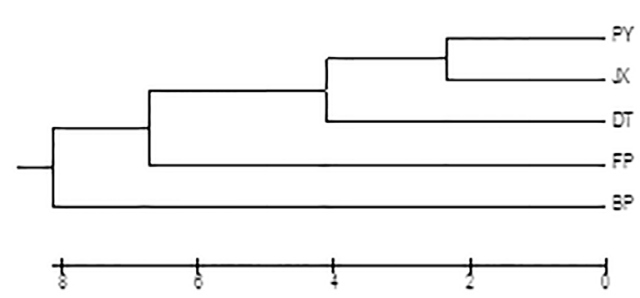

Figure 1. Clustering tree based on the shell nacre color parameters. PY: Poyang Lake wild population; JX: Hyriopsis schlegelii population; DT: Dongting Lake wild population; FP: cultured population; BP: breeding population.

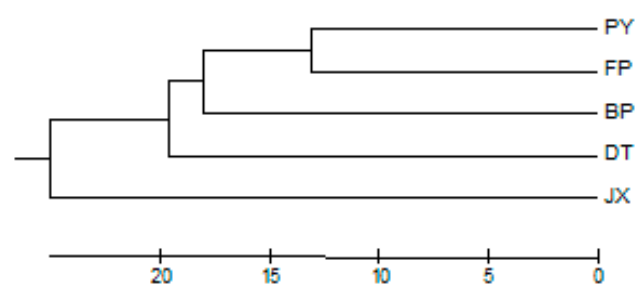

Figure 2. UPGMA (unweighted pair group method with arithmetic mean) tree based on Nei's genetic distances. PY: Poyang Lake wild population; FP: cultured population; BP: breeding population; DT: Dongting Lake wild population; JX: Hyriopsis schlegelii population.

\section{Analysis of population genetic structures}

In this study, hypothetical $K$ values between 2 and 5 were calculated, and 10 repeats were set. Based on an analysis of the trends in the parameters corresponding to the $K$ value, an obvious inflection point was found when $K=4$. This indicates that all the individuals tested in this study could be optimally classified into four theoretical groups. Comparative diagrams of the genetic results achieved with the optimal grouping $K=4$ and the minimum grouping $K$ $=2$ are shown in Figure 3. As can be seen in Figure 3, the genetic structures of the PY and FP populations were similar. However, there were significant differences among the BP, DT, and JX populations, and the genetic structures of these three populations were relatively independent.
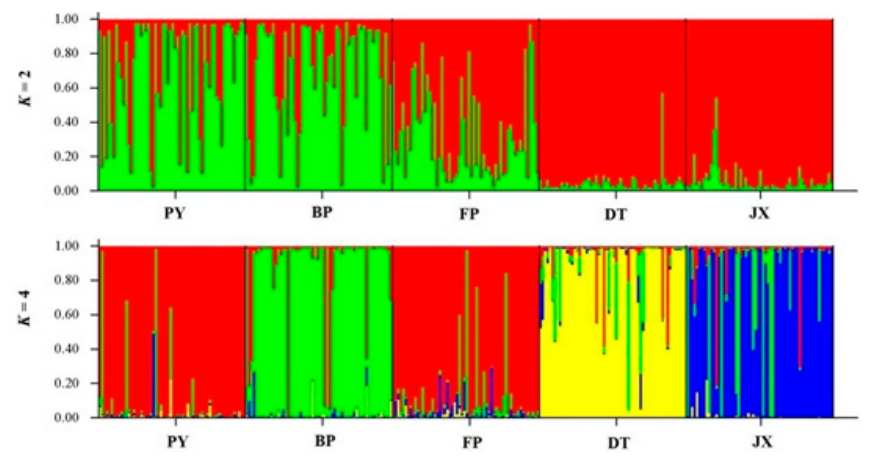

Figure 3. Genetic structures of each population under different hypothetical $K$ values. PY: Poyang Lake wild population; JX: Hyriopsis schlegelii population; DT: Dongting Lake wild population; FP: cultured population; BP: breeding population.

Genetics and Molecular Research 15 (4): gmr15048390 


\section{DISCUSSION}

\section{Analysis of shell color variation}

Mussel shell color is variable, not only between species, but also between different populations of the same species, and even on the left and right sides of the same species (Clarke, 1965). In this study, the average values for the nacre color parameters differed nonsignificantly between the left and right sides of the shells in each mussel population $(\mathrm{P}>0.05)$. Based on the variations and heritability of mussel shell color, phenotypic differences in this characteristics are more appropriate genetic markers for group classification and variety breeding than morphological markers, such as those used for clams (Sokolowski et al., 2002), pacific oyster (Evans et al., 2009), pearl oyster (Gu et al., 2011), and scallops (Qin et al., 2007; Yuan et al., 2012). Our results showed that each color parameter (except $\mathrm{L}^{*}$ and $\mathrm{dE}^{*}$ in DT) of the breeding population was significantly different from that of the other populations, while the color parameters showed no significant difference among the PY, DT, FP, and JX populations. Therefore, the germplasm resources should be evaluated by coupling shell color with genetic analysis.

\section{Analysis of population genetic diversity}

In this study, the average $N_{\mathrm{A}}$ at 15 microsatellite loci was found to be 36.67 , and PIC was between 0.607 and 0.974 . All loci were highly polymorphic and contained abundant genetic information (PIC > 0.5) (Botstein et al., 1980), and could be effectively used to analyze the genetic diversity and structure in all populations. In the PY population, the average $N_{\mathrm{A}}$ was 19.00 , and the average $H_{\mathrm{O}}$ and $H_{\mathrm{E}}$ values were 0.829 and 0.876 , respectively. The reported average $N_{\mathrm{A}}$ in the PY population was 21.40 , and the average $H_{\mathrm{O}}$ and $H_{\mathrm{E}}$ values were 0.7848 and 0.8127 , respectively (Luo, 2012). These two sets of results are consistent. Wang et al. (2007) reported that $H_{\mathrm{O}}, H_{\mathrm{E}}$, and PIC of the PY and the DT populations were lower than those reported in the present study. In this study, we used 15 pairs of microsatellite primers and gene typing, whereas Wang et al. (2007) used nine pairs of primers and polyacrylamide gel electrophoresis, which has lower resolution than the genotyping technique. The different numbers of microsatellites and the different detection methods used may explain the lack of consistency between the results of these studies.

Understanding genetic biodiversity is an important foundation for the evaluation of germplasm resources, and genetic diversity reflects the adaptive capacity of a species to their environment (Zhao et al., 2006). Overall, the five populations investigated in the present study displayed high levels of polymorphism, indicative of good germplasm resources. There was no decline in the genetic diversity of the BP relative to that of the wild populations, indicating that the breeding method used is reasonable and potentially applicable to further breeding. Compared with the genetic diversity observed in the wild populations, the diversity in the BP warrants further study. If a breeding population cannot maintain its abundant genetic diversity, certain traits may regress, reducing its adaptive capacity to its environment, and ultimately, resulting in breeding failure (Frankel and Soule, 1981). For many reasons, including limitations of the breeding scale and the environment, as well as a lack of scientific management, the genetic diversity of a breeding population is usually lower than that of wild populations, as observed in abalone (Li et al., 2007), oyster (Xiao et al., 2011), and Pacific oyster (C. gigas) (Miller et al., 2014). In contrast, some researchers have shown that the genetic diversity of Pinctada martensii is not significantly different from that of wild populations under artificial-

Genetics and Molecular Research 15 (4): gmr15048390 
breeding conditions (Yu and Chu, 2006a,b). Furthermore, some cultured varieties have genetic diversity that is higher than that of the corresponding wild populations (Peter et al., 2007; Gawenda et al., 2012). In conclusion, the genetic diversity of the artificial-breeding population has different development directions, and its tendency to decline should not be considered inevitable. Our results demonstrate that the genetic diversity of an $\mathrm{H}$. cumingii-breeding population is similar to that of wild populations. Both possess abundant genetic information, although at lower levels than observed in the cultured population. Presumably, these results arise from the parental resources used for breeding, which are obtained from many regions used by local farmers, and the mixed germplasm resources.

\section{Genetic variation among populations}

The genetic differentiation index $\left(F_{\mathrm{ST}}\right)$ is an important parameter used to evaluate the degree of genetic differentiation among populations. The genetic differentiation indices of each $H$. cumingii population and the $H$. schlegelii population were greater than 0.05 , which indicates moderate differentiation. The genetic differentiation between the $H$. cumingii populations and the $H$. schlegelii population was significantly higher than that between the $H$. cumingii populations. The genetic differentiation index was 0.0452 between the BP and the PY population, and 0.0504 between the BP and the DT population. Both indicate moderate differentiation. The BP were the base populations of PY and DT. After five generations of breeding, the genetic differentiation index indicated close to moderate differentiation, implying that significant variations had appeared in the genetic structure of the BP. Some researchers have also found that the genetic differentiation index between cultivated and wild Mytilus galloprovincialis populations revealed significant heterogeneity (Giantsis et al., 2012). Nei's genetic distances among the populations, and the corresponding UPGMA tree, show that the genetic distances between the $H$. cumingii populations and the $H$. schlegelii population was greatest, whereas that between the PY population and the cultured population was the shortest, and they clustered most closely. Many reports have shown that the PY and DT populations have large morphological differences and genetic distances, and do not cluster phylogenetically on the same branch (Qian et al., 2003). Our results are consistent with this observation.

The STRUCTURE software conducts population simulations based on the individual genetic composition of a population, which are not affected by the number of samples. It is an ideal tool for the analysis of population genetic structures (Evanno et al., 2005). A simulation analysis of each population was conducted, and all the samples in this study were classified into four theoretical populations. This result supports the clustering on the UPGMA tree, and is consistent with the genetic differentiation results. Thus, the PY population has a similar genetic structure to that of the cultured population, and the BP is significantly different from either of the base populations from PY and DT.

The genetic differentiation of genetic-ecological populations (wild population, cultured population, and breeding population) is significant, while the identification of populations and the genetic backgrounds of these species are limited by shell nacre polymorphisms and microsatellite markers; therefore, new markers should be exploited.

\section{Conflicts of interest}

The authors declare no conflict of interest.

Genetics and Molecular Research 15 (4): gmr15048390 


\section{ACKNOWLEDGMENTS}

Research supported by the National Science and Technology Support Program (\#2012BAD26B04), the National Natural Science Foundation of China (\#31272657), Shanghai Universities Knowledge Service Platform (\#ZF1206), and the Project of Shanghai Engineering and Technology Center for Promoting Ability (\#13DZ2280500).

\section{REFERENCES}

Bai ZY, Han XK, Luo M, Lin JY, et al. (2015). Constructing a microsatellite-based linkage map and identifying QTL for pearl quality traits in triangle pearl mussel (Hyriopsis cumingii). Aquaculture 437: 102-110. http://dx.doi. org/10.1016/j.aquaculture.2014.11.008

Botstein D, White RL, Skolnick M and Davis RW (1980). Construction of a genetic linkage map in man using restriction fragment length polymorphisms. Am. J. Hum. Genet. 32: 314-331.

Clarke A (1965). The scallop superspecies Aequipecten irradians (Lamarck). Malacologia 2: 161-188.

Evanno G, Regnaut S and Goudet J (2005). Detecting the number of clusters of individuals using the software STRUCTURE: a simulation study. Mol. Ecol. 14: 2611-2620. http://dx.doi.org/10.1111/j.1365-294X.2005.02553.x

Evans S and Langdon C (2006). Effects of genotype x environment interactions on the selection of broadly adapted Pacific oysters (Crassostrea gigas). Aquaculture 261: 522-534. http://dx.doi.org/10.1016/j.aquaculture.2006.07.022

Evans S, Camara MD and Langdon CJ (2009). Heritability of shell pigmentation in the Pacific oyster, Crassostrea gigas. Aquaculture 286: 211-216. http://dx.doi.org/10.1016/j.aquaculture.2008.09.022

Frankel O and Soule M (1981). Conservation and Evolution. Cambridge University Press, Cambridge.

Fu Q (2014). The study on the biological effect and genetic mechanism of inbreeding depression of Patinopecten Yessoensis. Dissertation (In Chinese), Ocean University of China.

Garcia RM and Winkler FM (2012). Association between shell color of breeds (Lamarck, 1819) and the survival, growth and larval development of their progenies. Lat. Am. J. Aquat. Res. 40: 367-375. http://dx.doi.org/10.3856/vol40issue2-fulltext-11

Gawenda I, Schröder-Lorenz A and Debener T (2012). Markers for ornamental traits in Phalaenopsis orchids: population structure, linkage disequilibrium and association mapping. Mol. Breed. 30: 305-316.

Giantsis IA, Kravva N and Apostolidis AP (2012). Genetic characterization and evaluation of anthropogenic impacts on genetic patterns in cultured and wild populations of mussels (Mytilus galloprovincialis) from Greece. Genet. Mol. Res. 11: 3814-3823. http://dx.doi.org/10.4238/2012.August.17.14

Gu ZF, Shi YH, Wang SY and Wang AM (2011). Heritable characteristics in the pearl oyster Pinctada martensii: comparisons of growth and shell morphology of Chinese and Indian populations, and reciprocal crosses. J. Shellfish Res. 30: 241-246. http://dx.doi.org/10.2983/035.030.0207

Kalinowski ST, Taper ML and Marshall TC (2007). Revising how the computer program CERVUS accommodates genotyping error increases success in paternity assignment. Mol. Ecol. 16: 1099-1106. http://dx.doi.org/10.1111/ j.1365-294X.2007.03089.x

Li Q, Xu K and Yu R (2007). Genetic variation in Chinese hatchery populations of the Japanese scallop (Patinopecten yessoensis) inferred from microsatellite data. Aquaculture 269: 211-219. http://dx.doi.org/10.1016/j. aquaculture.2007.04.017

Li XL, Bai ZY, Luo HR, Wang GL, et al. (2014). Comparative analysis of total carotenoid content in tissues of purple and white inner-shell color pearl mussel, Hyriopsis cumingii. Aquacult. Int. 22: 1577-1585. http://dx.doi.org/10.1007/ $\underline{\text { s10499-014-9766-6 }}$

Liu X, WuF, Zhao H, Zhang G, et al. (2009). A novel shell color variant of the Pacific abalone Haliotis discus hannai Inosubject to genetic control and dietary influence. J. Shellfish Res. 28: 419-424. http://dx.doi.org/10.2983/035.028.0226

Luo M (2012). Isolation of Microsatellite Markers and Population Genetic Structure Analysis between Sexes and Ages in Hyriopsis cumingii (In Chinese). Dissertation, Huazhong Agriculture University.

McGinty EL, Evans BS, Taylor JUU and Jerry DR (2010). Xenografts and pearl production in two pearl oyster species, $P$. maxima and P. margaritifera: Effect on pearl quality and a key to understanding genetic contribution. Aquaculture 302: 175-181. http://dx.doi.org/10.1016/j.aquaculture.2010.02.023

Miller PA, Elliott NG, Vaillancourta RE, Kube PD, et al. (2014). Genetic diversity and pedigree assignment in tetraploid Pacific oysters (Crassostrea gigas). Aquaculture 20: 318-324. http://dx.doi.org/10.1016/j.aquaculture.2014.06.025

Nei M (1978). Estimation of average heterozygosity and genetic distance from a small number of individuals. Genetics 89: 583-590.

Genetics and Molecular Research 15 (4): gmr15048390 
Newkirk GM (1980). 'Genetics of Shell Color in Mytilus Edulis L. And the Association of Growth Rate with Shell Color'. J. Exp. Mar. Biol. Ecol. 47: 89-94. http://dx.doi.org/10.1016/0022-0981(80)90140-9

Peter C, Bruford M, Perez T, Dalamitra S, et al.; ECONOGENE Consortium (2007). Genetic diversity and subdivision of 57 European and Middle-Eastern sheep breeds. Anim. Genet. 38: 37-44. http://dx.doi.org/10.1111/j.13652052.2007.01561.x

Qian RH, Li JL, Dong ZG, Zheng HF, et al. (2003). Morphological variations analysis among Hyriopsis cumingii in five large lakes. Oceanol. Limnol. Sin. 34: 436-460.

Qin Y, Liu X, Zhang H, Zhang G, et al. (2007). Identification and mapping of amplified fragment length polymorphism markers linked to shell color in bay scallop, Argopecten irradians irradians (Lamarck, 1819). Mar. Biotechnol. (NY) 9: 66-73. http://dx.doi.org/10.1007/s10126-006-6076-7

Scheil AE, Hilsmann S, Triebskorn R and Köhler HR (2013). Shell colour polymorphism, injuries and immune defense in three helicid snail species, Cepaea hortensis, Theba pisana and Cornu aspersum maximum. Results Immunol. 3 : 73-78. http://dx.doi.org/10.1016/j.rinim.2013.06.002

Sokolowski A, Fichet D, Garcia-Meunier P, Radenac G, et al. (2002). The relationship between metal concentrations and phenotypes in the Baltic clam Macoma balthica (L.) from the Gulf of Gdansk, southern Baltic. Chemosphere 47: 475-484.http://dx.doi.org/10.1016/S0045-6535(02)00002-4

Tamura K, Dudley J, Nei M and Kumar S (2007). MEGA4: Molecular Evolutionary Genetics Analysis (MEGA) software version 4.0. Mol. Biol. Evol. 24: 1596-1599. http://dx.doi.org/10.1093/molbev/msm092

Wada KT and Komaru A (1994). Effect of selection for shell coloration on growth rate and mortality in the Japanese pearl oyster, Pinctada fucata martensii. Aquaculture 125: 59-65. http://dx.doi.org/10.1016/0044-8486(94)90282-8

Wang GL, Yuan YM and Li JL (2007). SSR analysis of genetic diversity and phylogenetic relationship among different populations of Hyriopsis cumingii from the Five Lakes of China. J. Fish. China 31: 152-159.

Winkler FM, Estévez BF, Jollán LB and Garrido JP (2001). Inheritance of the general shell color in the scallop Argopecten purpuratus (Bivalvia: Pectinidae). J. Hered. 92: 521-525. http://dx.doi.org/10.1093/ihered/92.6.521

Xiao J, Cordes JF, Moss JA and Reece KS (2011). Genetic diversity in US hatchery stocks of Crassostrea ariakensis (Fujita, 1913) and comparison with natural populations in Asia. J. Shellfish Res. 30: 751-760. http://dx.doi. org $/ 10.2983 / 035.030 .0315$

$\mathrm{Yu} \mathrm{DH}$ and $\mathrm{Chu} \mathrm{KH}$ (2006a). Genetic variation in wild and cultured populations of the pearl oyster Pinctada fucata from southern China. Aquaculture 258: 220-227. http://dx.doi.org/10.1016/j.aquaculture.2006.03.024

Yu DH and Chu KH (2006b). Low genetic differentiation among widely separated populations of the pearl oyster Pinctada fucata as revealed by AFLP. J. Exp. Mar. Biol. Ecol. 333: 140-146. http://dx.doi.org/10.1016/j.jembe.2005.12.046

Yuan T, He M and Huang L (2012). Identification of an AFLP fragment linked to shell color in the noble scallop Chlamys nobilis Reeve. J. Shellfish Res. 31: 33-37. http://dx.doi.org/10.2983/035.031.0104

Zhao R, Cheng Z, Lu W and Lu B (2006). Estimating genetic diversity and sampling strategy for a wild soybean (Glycine soja) population based on different molecular markers. Chin. Sci. Bull. 51: 1219-1227. http://dx.doi.org/10.1007/ s11434-006-1219-9

Zhu WB (2011). The study on the affects of shell nacre color to pearl color in two varieties of Hyriopsis cumingii (In Chinese). Dissertation, Shanghai Ocean University.

Genetics and Molecular Research 15 (4): gmr15048390 